\title{
PRODUÇÃO DE ENTEROTOXINA TERMOESTÁVEL, HEMOLISINAS, COLICINA E FATORES DE COLONIZAÇÃO EM AMOSTRAS DE Escherichia coli ISOLADAS DE LEITÕES COM DIARRÉIA NO SUDOESTE DO PARANÁ
}

\author{
PRODUCTION OF THERMOSTABLE ENTEROTOXIN, HEMOLISINS, COLICIN \\ AND FIMBRIAE IN STRAINS OF Escherichia coli ISOLATES OF PIGLETS WITH \\ DIARRHEA OF SOUTHWEST PARANA
}

\author{
Benito Guimarães de BRITO ${ }^{*}$ \\ Kelly Cristina TAGLIARI ${ }^{2}$ \\ Milene Martins BERBEL ${ }^{3}$ \\ Roberta Lemos FREIRE ${ }^{4}$
}

\begin{abstract}
RESUMO
A E. coli é o principal agente infeccioso envolvido nas diarréias dos leitões. A patogenicidade deste microrganismo é determinada por diversos fatores de virulência, entre os quais destacam-se a presença dos fatores de colonização e toxinas. Nesta pesquisa foram avaliadas 140 cepas de $E$. coli isoladas de 82 leitões lactentes e 58 recém-desmamados com diarréia em granjas do Sudoeste do Paraná. A detecção da enterotoxina termoestável foi realizada em camundongos neonatos e a colicina verificada em ensaio em ágar com crescimento cruzado em meio semi sólido. Os fatores de colonização foram avaliados através da técnica de microhemaglutinação frente a eritrócitos de diferentes espécies animais. Em $37(26,4 \%)$ e 26 (18,6\%) amostras foram verificadas atividade hemolítica e colicinogênica respectivamente. A toxina termoestável foi sintetizada por apenas $17(12,1 \%)$ amostras. A presença de fatores de colonização manose resistente foi observada em 87 (62,1\%) amostras analisadas e 41 (29,3\%) amostras expressaram fímbria tipo 1.
\end{abstract}

Palavras-chave: Escherichia coli, leitões, diarréia, patogenicidade.

\begin{abstract}
Escherichia coli is the most prevalent infectious agent in cases of diarrhoea in piglets. The virulence of this microrganism is determined by several determinants, specially fimbriae and toxins. In the present work, we analized $140 \mathrm{E}$. coli strains obtained from 82 suckling piglets and from 58 piglets with post-wening diarrhoea in farms located in the southwestern region of the State of Paraná, Brazil. The detection of the thermostable toxin was performed through the infant mouse test and colicin detection using the agar overlay method. The colonization factors were assayed through the microagglutination test, using different sources of red blood cells. In 37 $(26,4 \%)$ and $26(18,6 \%)$ of the samples, the presence of hemolisin and colicinogenic activity were detected, respectively. Thermostable enterotoxin was produced by $17(12,1 \%)$ of the samples. Mannose resistant fimbriae was detected in $87(62,1 \%)$ of the samples and 41 $(29,3 \%)$ of the samples expressed type 1 fimbriae.
\end{abstract}

Key-words: Escherichia coli, piglets, diarrhoea, pathogenicity.

\footnotetext{
${ }^{1}$ Med. Vet., Dr. - Pesquisador do Departamento de Medicina Veterinária Preventiva, Centro de Ciências Agrárias, Universidade Estadual de Londrina, Caixa postal 6001, CEP: 86.051-970, Londrina - PR, Brasil. E-mail: bgbrito@zipmail.com.br *Autor para correspondência;

${ }^{2}$ Bióloga, Dra. - Pesquisadora do Laboratório Ecolvet - Análises Microbiológicas, Ambientais e Veterinárias. Rua Quatá, 78, 86.062-580. Londrina PR, Brasil;

${ }^{3}$ Estagiária de Iniciação Científica - Acadêmica do Curso de Medicina Veterinária da Universidade Estadual de Londrina, Caixa postal 6001, CEP: 86.051-970, Londrina - PR, Brasil;

${ }^{4}$ Med. Vet., Dra. - Docente do Departamento de Medicina Veterinária Preventiva, Centro de Ciências Agrárias, Universidade Estadual de Londrina, Caixa postal 6001, CEP: 86.051-970, Londrina - PR, Brasil.
} 


\section{INTRODUÇÃO}

A colibacilose é uma das principais causas de diarréia dos leitões em granjas do Sudoeste do Paraná (BRITO et al., 1995). A patogenicidade da E. coli está relacionada à sua capacidade de colonizar o epitélio intestinal, através de antígenos de superfície, de estrutura protéica, denominados fímbrias.

A expressão de determinadas fímbrias é influenciada pelas condições do crescimento " in vitro" como o pH, a osmolaridade do meio, a aeração e a temperatura de cultivo (GAASTRA e GRAAF, 1982; ARCHER, 1996). Na detecção de fímbrias tem sido utilizados testes que avaliam a expressão fenotípica: hemaglutinação, hidrofobicidade, adesão celular, sorológicos (DE GRAFF e MOOI, 1986; VAN LOOSDRECHT et al, 1987; QADRI et al., 1994) e características genotípicas: hibridização de colônias com sondas e PCR (DAIGLE et al., 1994; SHIN et al., 1994). O teste de hemaglutinação tem sido utilizado como método de triagem de expressão de fímbrias (EVANS et al., 1979; BRITO et al., 2000).

Baseado na atividade hemaglutinante, as fímbrias de $E$. coli foram classificadas em três categorias: fímbrias não hemaglutinantes, como exemplo a fímbria 987P; fímbrias que têm a sua aglutinação com eritrócitos inibida pela D-manose, designadas manose-sensíveis (HAMS) ou fímbrias tipo 1 e as fímbrias que não tem a hemaglutinação inibida pela manose, chamadas manose-resistente (HAMR) (MORRIS, 1983).

As fímbrias HAMR compreendem um grupo heterogêneo de estruturas bacterianas que se ligam a carbohidratos, com exceção a D-manose, presentes nos receptores dos eritrócitos de diferentes espécies animais (MORRIS, 1983; QADRI et al., 1994). As cepas produtoras de fímbrias manose resistente a $37^{\circ} \mathrm{C}$, deixam de expressar esta característica quando são cultivadas a $18{ }^{\circ} \mathrm{C}$ (JONES e RUTTER, 1974). Em suínos as fímbrias F4, F5, F6, F18a,b, F18a,c, $F 41, F 42$ e F165 estão relacionadas a distúrbios entéricos (POST et al., 2000).

Outros fatores de virulência importantes na patogenia das enfermidades são as toxinas de E.coli, as quais classificam-se em endotoxinas e exotoxinas, e têm papel importante nas diarréias dos suínos (GYLES, 1992). Smith e Halls (1967) foram os primeiros a identificar uma proteína secretada pela bactéria, responsável pelo acúmulo de líquido em testes realizados em alças de intestino de coelho e suíno. Além disso, demonstraram que esta toxina mantinha sua atividade após aquecimento a $100{ }^{\circ} \mathrm{C}$ durante 30 minutos, denominada de toxina termoestável (STa).

A hemolisina é freqüente em amostras de $E$. coli uropatogênicas (UPEC) e enterohemorrágicas (EHEC) isoladas de infecções urinárias e patologias entéricas dos suínos (BRITO et al., 1999; KUHNERT et al., 2000). A E. coli pode produzir quatro tipos distintos de hemolisinas, as quais são classificadas conforme a fase de crescimento em que sintetizam a hemolisina e o tipo de eritrócito que lisam. A alfahemolisina é produzida na fase logarítima, a betahemolisina, gama-hemolisina e enterohemolisina são produzidas na fase estacionária. A beta-hemolisina provoca a hemólise de eritrócitos de cavalo, coelho e ovelha, enquanto que a gama-hemolisina e a enterohemolisina lisam eritrócitos de cavalo-ovelha e ovelha-coelho, respectivamente (LUDWIG e GOEBEL, 1997).

Bacteriocinas são toxinas protéicas que têm ação letal sobre espécies de bactérias sensíveis. As bacteriocinas produzidas pela $E$. coli são denominadas de colicinas, a produção de colicina $\mathrm{V}$ mediada pelo plasmidio Col $\mathrm{V}$ é uma característica associada com a invasão e patogenicidade da E. coli (VIDOTTO et al., 1990).

Com base na literatura, este trabalho teve por objetivo determinar a ocorrência de fímbrias hemaglutinantes, produção de colicina, hemolisinas e enterotoxina termoestável em amostras de $E$. coli isoladas de leitões com diarréia.

\section{MATERIAL E MÉTODOS}

Foram utilizadas 140 cepas de E. coli, sendo isoladas 82 amostras das fezes de leitões lactentes e 58 amostras de leitões recém-desmamados com diarréia, em vinte e uma granjas de ciclo completo, criados em sistema confinado, que não utilizavam medicamentos na ração contra diarréia e localizadas na região Sudoeste do Paraná.

$O$ isolamento das cepas de $E$. coli foi realizado em placas de ágar sangue ovino a $5 \%$ e ágar Mac Conkey, após incubação durante 24 horas a $37^{\circ} \mathrm{C}$. Foram utilizadas as placas que tiveram apenas crescimento de colônias com características de E. coli. Estas colônias foram submetidas à coloração de Gram, identificadas, segundo as recomendações de Edward e Ewing (1972), e estocadas em meio Dorset à temperatura ambiente, por no máximo seis meses, até a realização das demais análises.

A produção de STa foi obtida conforme descrito por Dean et al. (1972). Cepas de E. coli foram semeadas em meio Caye e incubadas durante 18 horas a $37^{\circ} \mathrm{C}$ sob agitação constante. A extração foi realizada pela centrifugação do meio de cultivo a 6000 $x \mathrm{~g}$, durante 30 minutos. O sobrenadante obtido foi inoculado por via intragástrica em camundongos neonatos. Os animais foram mantidos numa estufa a $35{ }^{\circ} \mathrm{C}$ por 3 horas, e após os animais foram sacrificados com éter sulfúrico, necropsiados e os intestinos e carcaças pesados separadamente para determinação da relação peso dos intestinos / peso das carcaças. Os valores iguais ou superiores a 0,085 foram considerados como positivos para STa (GIANELLA, 1976).

A produção de colicina pelas cepas foi avaliada conforme descrito por Vidotto et al. (1990). As amostras de $E$. coli foram inicialmente cultivadas em meio Caldo Soja Tripticaseína (TSB) a $37^{\circ} \mathrm{C}$ durante 
18 horas e posteriormente semeadas em vários pontos de uma placa contendo meio Agar Soja Tripticaseína (TSA) e incubadas nas mesmas condições. Após o período de incubação, as placas foram invertidas e $1 \mathrm{ml}$ de clorofórmio foi adicionado nas respectivas tampas. Estas foram mantidas fechadas por aproximadamente 30 minutos, resultando em morte das bactérias. Decorrido este período, as placas foram mantidas entreabertas a $37{ }^{\circ} \mathrm{C}$ durante 60 minutos para evaporação do clorofórmio residual. Em cada uma das placas foram vertidos $3 \mathrm{ml}$ de TSA semisólido a aproximadamente $45^{\circ} \mathrm{C}$, adicionado de 100 $\mu \mathrm{l}$ da amostra indicadora de E. coli 2280 (linhagem padrão sensível à colicina), a qual foi cultivada previamente em meio TSB durante 18 horas a $37^{\circ} \mathrm{C}$. As placas foram incubadas a $37^{\circ} \mathrm{C}$ durante 18 horas e a produção de bacteriocina visualizada pela presença de halo de inibição de crescimento da bactéria indicadora.

As fímbrias foram pesquisadas através da técnica de microhemaglutinação, com suspensões a $1 \%$ de hemácias de suíno, galinha e cavalo em presença de D-manose $1 \%$. As suspensões de hemácias foram obtidas de sangue fresco, após coleta em solução anticoagulante de Alsever e lavagens em solução de PBS, $\mathrm{pH} 7,3$. As culturas bacterianas foram crescidas em meio CFA, meio mínimo sólido, ágar glicosado tamponado e meio Minca a $37^{\circ} \mathrm{C}$ durante 24 horas.
O teste foi realizado em microplaca de base em "U" de 96 escavações, em triplicata para cada cepa e durante todo o procedimento a placa permaneceu em banho de gelo. Foram realizadas diluições seriadas em PBS a partir de 1:2 até 1:256, em volumes de $50 \mu \mathrm{l}$, da suspensão bacteriana padronizada na escala 4 de McFarland. Nas cepas cultivadas em meio CFA, meio mínimo sólido, ágar glicosado tamponado e meio Minca, foram adicionados $50 \mu \mathrm{L}$ das suspensões de hemácias a $1 \%$ de suíno, galinha e cavalo respectivamente. $O$ resultado foi observado pela hemaglutinação após 2 horas sob refrigeração. As seguintes cepas padrões foram utilizadas como controles positivo para cada fímbria : BK95 (K88), BK99 (K99), 567/7 (F42) e BK99 (fímbria tipo 1); e a amostra K12-711 foi utilizada como controle negativo dos testes (Tabela 1). As cepas com título igual ou superior a 1:4 foram consideradas hemaglutinantes (BRITO et al., 2000).

A atividade hemolítica foi verificada conforme descrito por Ludwig e Goebel (1997). As amostras foram cultivadas em ágar sangue com suplementação de $10 \%$ de sangue de cavalo, ovelha, coelho e incubadas a $37^{\circ} \mathrm{C}$ por 24 horas. Cinco horas após o início da incubação foi realizada uma leitura inicial, com reavaliações após 24 e 48 horas do início da incubação. Foram consideradas positivas as amostras capazes de induzir halo de hemólise.

TABELA 1 - Meios de cultivo, hemácias e cepas padrões usadas nos testes de microhemaglutinação.

\begin{tabular}{lccc}
\hline Meio de cultivo & Hemácias & Cepa padrão positiva & Cepa padrão negativa \\
\hline Caldo Soja Tripticaseína & Cobaia & BK99 (fímbria tipo 1) & K12-711 \\
Ágar glicosado tamponado & Ovino & BK95 (K88) & K12-711 \\
Meio mínimo sólido & Galinha & $567 / 7$ (F42) & K12-711 $1^{1}$ \\
Meio Minca & Eqüino & BK99 (K99) & K12-711 \\
\hline
\end{tabular}

1BRITO et al. (1999); 'BRRITO et al. (2001b); ${ }^{3}$ BRITO et al. (2001a); ' 4 LEITE et al. (1988).

A análise estatística dos resultados de ocorrência de enterotoxina termoestável, colicina, colicina $\checkmark$ e hemolisinas, nas amostras de $E$. coli isoladas de leitões na fase de amamentação e após desmamados, foi realizada através do teste de $c^{2}$, teste exato de Fisher, com nível de significância de $\mathrm{P} £ 0.01$ e razão de chances (Odds ration - OR), através do Programa Estatístico Epilnfo, Center for Disease Control and Prevention, Atlanta, Georgia, EUA.

\section{RESULTADOS E DISCUSSÃO}

Os dados de hemaglutinação em presença e ausência de D-manose estão apresentados na Tabela 2. Das 140 cepas de E. coli estudadas, $42(30 \%)$ não apresentaram atividade hemaglutinante. Dados similares foram encontrados por Ueti (1997) que observou que $32,2 \%$ das cepas de $E$. coli isoladas de leitões com diarréia, não hemaglutinaram hemácias humanas, bovinas, ovinas, suínas, de galinha e de cobaia.

A presença de fímbria tipo 1 foi detectada em $41(29,3 \%)$ das cepas de $E$. coli, sendo que $18(12,9 \%)$ expressaram apenas este tipo de fímbria. Estes resultados estão de acordo com os obtidos por Martins et al. (2000) e demonstram que a fímbria tipo 1 é relativamente freqüente na população de cepas de $E$. coli que causam diarréia em leitões.

Oitenta e sete $(62,1 \%)$ cepas aglutinaram hemácias de diversas espécies em presença de $D$ manose. Estes resultados assemelham-se aos encontrados por Brito et al. (2000) que detectaram em 67,3\% das cepas de $E$. coli de leitões diarréicos de granjas do Paraná, atividade HAMR às hemácias de ovino, cobaia, eqüino e galinha. A freqüência de HAMR entre as cepas estudadas neste trabalho, na presença de hemácias de ovino, cobaia, eqüino e galinha, foi de $58,8 \% ; 32,3 \% ; 5,6 \%$ e $4,9 \%$ respectivamente. 
A presença de fímbria tipo 1 e a atividade HAMR foi verificada em $23(16,4 \%)$ cepas, sendo 21 $(15 \%)$ para hemácias de ovino, $1(0,7 \%)$ para hemácias de eqüino e $1(0,7 \%)$ para a associação de ovino e galinha.

A enterotoxina termoestável foi sintetizada por $17(12,1 \%)$ amostras, resultados são similares aos obtidos por Abuxapqui et al. (1997) e Martins et al.
(2000) que verificaram a presença desta toxina em $11,76 \%$ e $14,28 \%$ das amostras estudadas, respectivamente. A produção de colicina foi observada em $26(18,6 \%)$ das amostras e apenas em $6(3,6 \%)$ amostras verificou-se produção de colicina $\mathrm{V}$, resultados diversos daqueles obtidos por Martins et al. (2000) que verificaram a produção de colicinas e colicina $\mathrm{V}$ em $54,28 \%$ e $24,2 \%$ respectivamente.

TABELA 2 - Atividade hemaglutinante de cepas de E. coli isoladas de leitões com diarréia em granjas do Sudoeste do Paraná.

\begin{tabular}{lcc}
\hline Perfil de hemaglutinação & Número de amostras & Percentagem \\
\hline Não hemaglutinantes & 42 & 30,0 \\
Hemaglutinação manose-sensível & 41 & 29,3 \\
Hemaglutinação manose-resistente & 87 & 62,1 \\
Ovino & 46 & 32,9 \\
Ovino.galinha & 3 & 2,1 \\
Galinha & 2 & 1,4 \\
Cobaia.ovino & 15 & 21,0 \\
Cobaia.ovino.galinha & 2 & 1,4 \\
Cobaia & 9 & 6,4 \\
Eqüino.ovino & 1 & 0,7 \\
Eqüino & 2 & 1,4 \\
Eqüino.cobaia & 4 & 2,8 \\
Eqüino.cobaia.ovino & 4 & 0,7 \\
\hline
\end{tabular}

Das 140 amostras de E. coli estudadas 37 $(26,4 \%)$ sintetizaram alfa-hemolisina, sendo $7(8,5 \%)$ amostras provenientes de leitões lactentes e 30 $(51,7 \%)$ de animais recém-desmamados, conforme exposto na Tabela 3. Nenhuma amostra analisada produziu beta, gama e enterohemolisina. A partir da análise de OR verificou-se que as amostras de $E$. coli isoladas de leitões desmamados apresentaram 11,48 vezes mais chances de terem atividade hemolítica do que as amostras de $E$. coli isoladas de leitões lactentes. A presença deste fenótipo como marcador de clones virulentos tem sido utilizada por vários au- tores como indicador de patogenicidade (VAN DEN BOSCH et al., 1982; BEUTIN, 1991), entretanto os resultados obtidos neste trabalho indicam que esta característica de virulência somente pode ser considerada nas amostras originárias de leitões desmamados, uma vez que é baixa a ocorrência desta característica nas amostras de $E$. coli isoladas de leitões lactentes. Baseado nestes resultados pode-se concluir que a produção ou não de hemolisinas, não representa, quando isolado, critério seguro na seleção de cepas virulentas de E. coli, causadoras de diarréia entre leitões lactentes.

TABELA 3 - Percentagem de amostras de E. coli isoladas de leitões lactentes e desmamados com diarréia que apresentaram atividade hemolítica, colicinogênica e produção de enterotoxina temoestável.

\begin{tabular}{lcccc}
\hline Fase de criação & Hemolisina & Colicina & Colicina V & $\begin{array}{c}\text { Enterotoxina } \\
\text { Termoestável }\end{array}$ \\
\hline Lactentes & $7 / 82(8,5 \%)^{\mathrm{a}}$ & $17 / 82(20,7 \%)^{\mathrm{a}}$ & $4 / 82(4,9 \%)^{\mathrm{a}}$ & $10 / 82(12,2 \%)^{\mathrm{a}}$ \\
Desmamados & $30 / 58(51,7 \%)^{\mathrm{b}^{*}}$ & $9 / 58(15,5 \%)^{\mathrm{a}}$ & $2 / 58(2,4 \%)^{\mathrm{a}}$ & $7 / 58(12,1 \%)^{\mathrm{a}}$ \\
Total & $37 / 140(26,4 \%)$ & $26 / 140(18,6 \%)$ & $6 / 140(4,3 \%)$ & $17 / 140(12,1 \%)$ \\
\hline
\end{tabular}

${ }^{1}$ Valores com letras diferentes na mesma coluna, diferem $(P<0,01)$, no teste de $\chi^{2}$.

*Odds ratio: $11,48(4,20<\mathrm{OR}<32,63)$. 


\section{CONCLUSÕES}

A maioria das cepas estudadas neste trabalho apresentam atividade hemaglutinante, demonstrando que este teste pode ser utilizado como método de triagem de patogenicidade microbiana.
Nas cepas avaliadas neste estudo, observase alto percentual hemaglutinante a diversos eritrócitos em presença de D-manose, sendo que o eritrócito de ovino promoveu maior hemaglutinação.

A produção de hemolisina foi mais freqüente em amostras de $E$. coli isoladas de leitões desmamados.

\section{REFERÊNCIAS BIBLIOGRÁFICAS}

ABUXAPQUI, J.J.F.; HOIL, G.J.S.; FRANCO, M.A.P. et al. Frequency of adhesive factors and entero-toxins in strains of Escherichia coli isolated from piglets with diarrhea. Revista Latino Americana de Microbiologia, v.39,p.145-151, 1997.

ARCHER, D.L. Preservation microbiology and safety: evidence that stress enhances virulence and triggers adaptive mutations. Trends in Food Science \& Technology, v.7, n.3, p.91-5, 1996.

BEUTIN, L. The different hemolysins of Escherichia coli. Medical Microbiology Immunology, v. 180, p.167-182, 1991.

BRITO, B. G. de; FILIPPSEN, L. F.; MORES, N. Etiologia da diarréia de leitões lactentes em granjas suinícolas do sudoeste do Paraná. Semina, v.16, n.1, p.13-17, 1995.

BRITO, B.G. de; LEITE, D.S.; LINHARES, R.E.C. et al. Virulence factors of uropathogenic Escherichia coli strains isolated from pigs. Veterinary Microbiology, v.65, p.123-132, 1999.

BRITO, B.G. de; ALFIERI, A.A.; MÜLLER, E.E. et al. Fatores de virulência de Escherichia coli isoladas de leitões lactentes e recémdesmamados com diarréia em granjas do Estado do Paraná-Brasil. Arquivos Faculdade Veterinária UFRGS, v.28, n.2, p.76-85, 2000.

BRITO, B.G. de; VIDOTTO, M.C.; LEITE, D.S. Genotipagem dos fatores de virulência de amostras de E. coli isoladas de leitões lactentes com diarréia. In: CONGRESSO BRASILEIRO DE MEDICINA VETERINÁRIA, 28, Anais... Salvador : SBMV, 2001a. BRITO, B.G. de; TAGLIARI, K.C.; PIFFER, I.A. Caracterização da virulência da cepa de Escherichia coli-BK99. Ciência Rural, v.31, n.3, p. 455-459, 2001b

DAIGLE, F.; HAREL, J.; FAIRBROTHER, J.M. Expression and detection of pap-, sfa-, and afa-encoded fimbrial adhesin systems among uropathogenic Escherichia coli. Canadian Journal Microbiology, v.40, n.5, p.286-91, 1994.

DEAN, A.G., CHING, Y.C., WILLIANS, R.G., et al. Test for E. coli enterotoxin using infant mice: application in a study of diarrhea in children in Honolulu. Journal Infectious Diseases, v. 125, n. 4, p. 407-411, 1972.

DE GRAFF, F.K.; MOOI, F.R. The fimbrial adhesins of Escherichia coli. Advances Microbiology Physiology, v.28, p.65-143, 1986. EDWARDS, P.R.; EWING, W.H. Identification of Enterobacteriacea, 3 ed. Minneapolis: Burgess Publishers, 1972.

EVANS, D.J.; EVANS, D.G.; DU PONT, H.L. Hemagglutination patterns of enterotoxigenic and enteropathogenic Escherichia coli determined with human, bovine, chicken, and guinea pig erythrocytes in the presence and absence of mannose. Infection Immunity, v.23, n.2, p.336-46, 1979.

GAASTRA, W., DE GRAAF, F. K. Host-specific fimbrial adhesins of noninvasive enterotoxigenic Escherichia coli strains. Microbiology Review, v.46, n.2, p.129-161, 1982

GIANELLA, R.A. Suckling mouse model for detection of heat-stable Escherichia coli enterotoxin: characteristics of the model. Infection Immunity, v. 14, n. 1, p. 95-99, 1976.

GYLES, C.L. Escherichia coli cytotoxins and enterotoxins. Canadian Journal Microbiology, v.36, p.734-46, 1992.

JONES, G.W.; RUTTER, J.M. The association of $\mathrm{K}_{88}$ antigen with haemagglutinating activity in porcine strains of Escherichia coli. Journal General Microbiology, v.84, p.135-44, 1974.

KUHNERT, P.; BOERLIN, P.; FREY, J. Target genes for virulence assessment of Escherichia coli isolates from water, food and the environment. FEMS Microbiology Reviews, v.24, p.107-117, 2000.

LEITE, D.S.; YANO, T.; CASTRO, A.F.P. Production, purification and partial characterization of a new adhesive factor (F42) produced by enterotoxigenic Escherichia coli isolated from pigs. Annales de L'Institute Pasteur Microbiology, v.139,p.295-306, 1988.

LUDWIG, A.; GOEBEL, W. Haemolysins of Escherichia coli. In: SUSSMAN, M. Escherichia coli mechanisms of virulence. Cambridge:Cambridge University, 1997. p. 281-329.

MARTINS, M.F.; MARTINEZ-ROSSI, N.M.; FERREIRA, A. et al. Pathogenic characteristics of Escherichia coli strains isolated from newborn piglets with diarrhea in Brazil. Veterinary Microbiology, v.76, p.51-59, 2000.

MORRIS, J.A. Escherichia coli fimbrial adhesins. Pig News and Information., v.4, n.1, p.19-21, 1983.

POST, K.W.; BOSWORTH, B.T.; KNOTH, J.L. Frequency of virulence factors in Escherichia coli isolated from pigs with postweaning diarrhea and edema disease in North Carolina. Swine Health Production, v.8, n.3, p.119-120, 2000.

QADRI, F.; HAQUE, A.; FARUQUE, S.M. et al. Hemagglutination properties of enteroaggregative Escherichia coli. Journal Clinical Microbiology, v.32, n2, p.510-514, 1994.

SHIN, S.J.; CHANG, Y.; TIMOUR, M. et al. Hibridization of clinical Escherichia coli isolates from calves and piglets in New York State with gene probes for enterotoxins (STaP, STb, LT), Shiga-like toxins (SLT-I, SLT-II) and adhesion factors $\left(\mathrm{K}_{88}, \mathrm{~K}_{99}, \mathrm{~F}_{41}, 987 \mathrm{P}\right)$. Veterinary Microbiology, v.38, n.3, p.217-225, 1994.

SMITH, H.W.; HALLS, S. Observations by the ligated intestinal segment and oral inoculation methods on Escherichia coli infections in pigs, calves, lambs and rabitts. Journal Pathology Bacteriology, v.93, p.499-529, 1967.

UETI, M.W. Pesquisa de toxinas em amostras de Escherichia coli isoladas de leitões com diarréia. Londrina: Universidade Estadual de Londrina, 1997. Tese de Mestrado. 
BRITO, B.G. et al. Produção de enterotoxina termoestável...

VAN DEN BOSCH, J.F.; EMÖDY, L. KÉTYI, I. Virulence of haemolytic strains of Escherichia coli in various annimal models. FEMS Microbiology Letter, v.13, p.427-430, 1982.

VAN LOOSDRECHT, M.C.M.; LYKLEMA, J.; NORDE, W. et al. The role of bacterial cell wall hydrophobicity in adhesion. Applied Environmental Microbiology, v.53, n.8, p.1893-7, 1987.

VIDOTTO, M.C.; MÜLLER, E.E.; FREITAS, J.C. et al. Virulence factors of avian Escherichia coli. Avian Diseases, v.34, p.531-8, 1990.

Recebido em 12/12/2001

Aceito em 10/12/2003 